\title{
Pengembangan Indeks Penilaian Bank Sampah Skala Kota Studi Kasus Kota Bandung dan Kota Cimahi
}

\author{
MEGA PRANADITYA ${ }^{1}$, IWAN JUWANA ${ }^{1}$, SITI AINUN ${ }^{1}$ \\ 1. JurusanTeknikLingkungan, FakultasTeknikSipildanPerencanaan, \\ InstitutTeknologiNasional, Bandung \\ Email : megapranaditya11@gmail.com
}

\begin{abstract}
ABSTRAK
Bank sampah skalakotaadalah aplikasi pengelolaan sampahuntuk mengurangi sampah suatukotayang akan dibuang ke TPA. Penelitian ini bertujuan untuk menyempurnakan indeks sebelumnya. Dengan meninjau indikator sebelumnya melalui tinjauan pustaka, yang kemudian akan divalidasidengan metode AHP untuk menentukan pembobotan. Terdapat 4 kategorirespondenyaitu, professional expert, akademisi, instansi dan pihak bank sampah. Kajian ini menghasilkan tiga komponen, tiga belas indikator dan enam puluh satu sub-indikator teridentifikasi. Berdasarkan hasil AHP, bobot dari masingmasing komponen adalah Sistem Manajemen (40\%), Sistem Operasional (30\%) dan Fasilitas Bank Sampah (30\%). Jumlah indikator dari masing-masing komponen berkisar 4-5 indikator dengan bobot 15\%-35\%. Adapun sub indikator memiliki jumlah berkisar 2-8 dengan bobot 10\%-50\%.
\end{abstract}

Kata Kunci : Bank Sampah, Indeks, Metode AHP, Komponen, Indikator, Sub-Indikator

\begin{abstract}
Waste bank is one application of waste management by utilizing waste that is considered having re-sellvalues, which at the end can be used to reduce the waste dumped into landfill. Thus, a tool to assess the readiness of a waste bank to function at a city-scale is needed. This study aims to refine the previous index. This was done by first, reviewing previous indicator through literature review, which was then verified by the application of the AHP method which was usedwas also used to determine the weights for each indicator. The respondents for AHP applications were selected from four categories which were garbage expert, academics, intitutions and management representatives of waste bank. At the end of the study, three components, thirteen indicators and sixty one sub-indicators were identified. The name of the components and their respective weights are Management System (55\%), Operating System (25\%) and Waste Bank Facility (20\%). The number of indicators from each components ranged from 4 to 5 indicators with the weights range from $15 \%$ to $35 \%$. As for the sub indicators, they range from 2 to 8 sub indicators with the weights between $10 \%$ to $50 \%$.
\end{abstract}

Kata Kunci : Waste Bank, Index, AHP Method, Components, Indicators, SubIndicators 


\section{PENDAhUlUAN}

Bank sampah merupakan tempat pengelolaan sampah yang terintegrasi sebagai penerapan dari kegiatan Reduce, Reuse dan Recycle (3R) dengan tujuan untuk mengurangi sampah di sumbernya (Dewi, 2017; Juliandoni, 2013). Perencanaan pengembangan Bank Sampah Resik Kota Bandung dan Bank Sampah Induk Kota Cimahi memiliki peran yang sangat penting bagi sistem pengelolaan sampah dalam mengurangi timbulan sampah kota.

Saat ini telah terdapat indeks mengenai bank sampah resik (IBSR), dimana terdapat tiga komponen utama dalam indeks tersebut yaitu komponen kualitas konstruksi bangunan, komponen sistem manajemen dan komponen sistem operasional. Pada studi tersebut, tidak membahas tentang fasilitas pengolahan sampah. Selain itu, pembobotan pada setiap indikator dilakukan menggunakan analisis dekriptif dengan membagi nilai maksimum dengan jumlah indikator sehingga, setiap indikator memiliki bobot yang sama besarnya, padahal terdapat kemungkinan bahwa setiap indikator memiliki bobot yang berbeda.

Berdasarkan uraian tersebut, maka perlu dilakukan pengembangan indeks bank sampah skala kota (IBSSK) yang mengkaji ulang mengenai komponen apa saja yang dapat mempengaruhi suatu keberhasilan bank sampah skala kota. Setelah itu dilakukan validasi pada indeks yang telah dikembangkan tersebut dengan mengunakan metode Analytical Hierarchy Process (AHP).Metode AHP ini dapat digunakan dengan cara membuat kuesioner yang berupa perbandingan berpasangan yang nantinya akan diisi oleh empat kategori responden yang aktif dibidang pengelolaan sampah. Keempat bidang kategori tersebut adalah profesional expert, instansi, akademisi serta pengurus bank sampah.

Maksud dari studi ini adalah untuk melakukan penyusunan IBSSK berdasarkan pengembangan indeks sebelumnya. Tujuan menentukan komponen, indikator dan subindikator yang perlu ditambahkan berdasarkan IBSR, menentukan bobot pada masingmasing indeks yang telah diidentifikasi, serta melakukan uji coba indeks pada bank sampah yang dijadikan subjek penelitian.

\subsection{Pengumpulan data}

\section{METODOLOGI}

Pengumpulan data sekunder dilakukan dengan cara Desk Study. Desk Study dilakukan untuk menyusun kembali parameter-parameter yang akan dipakai dalam IBSSK. Terdapat literatur utama dan literatur penunjang dalam Desk Study. Literatur utama adalah sumber referensi dalam penyusunan IBSR. Sedangkan literatur penunjang diantaranya adalah peraturan, buku konsep bank sampah serta jurnal penelitian lainnya.

Data primer diperoleh dari hasil pengisian kuesioner oleh responden, dimana data primer tersebut berupa pemberian bobot mengenai komponen dan indikator. Selain itu, data primer lain diperoleh dari hasil uji coba indeks yang dilakukan pada bank sampah yang dijadikan subjek penelitian. Data primer tersebut dihasilkan berdasarkan hasil observasi langsung dilapangan.

\subsection{Penyusunan Indeks}

Terdapat tahapan yang perlu dilakukan dalam peyusunan indeks menurut Nasibu (2009) sebagai berikut :

1. Identifikasiulangkomponen

Meninjaudariliteraturutamayaitu IBSR, kemudianhasildaritinjauantersebut di review kembalipadaliteraturpenunjanglainnyasepertiperaturan, bukukonsep bank 
sampahsertajurnallainnya. Hal inidilakukanuntukmenetapkankomponen yang dinilaidapatmewakili IBSSK.

2. Identifikasiindikator

Padaindentifikasiindikator,

dilakukanpeninjauanpadaliteraturutamadanliteraturpenunjangsecarabersamaan.Beriku tmerupakancontohskema

menunjukancaradalammelakukanidentifikasiindikatordalamkomponensistemmanajem

en :

Tabel 1. Indikator dalam Komponen Sistem Manajemen
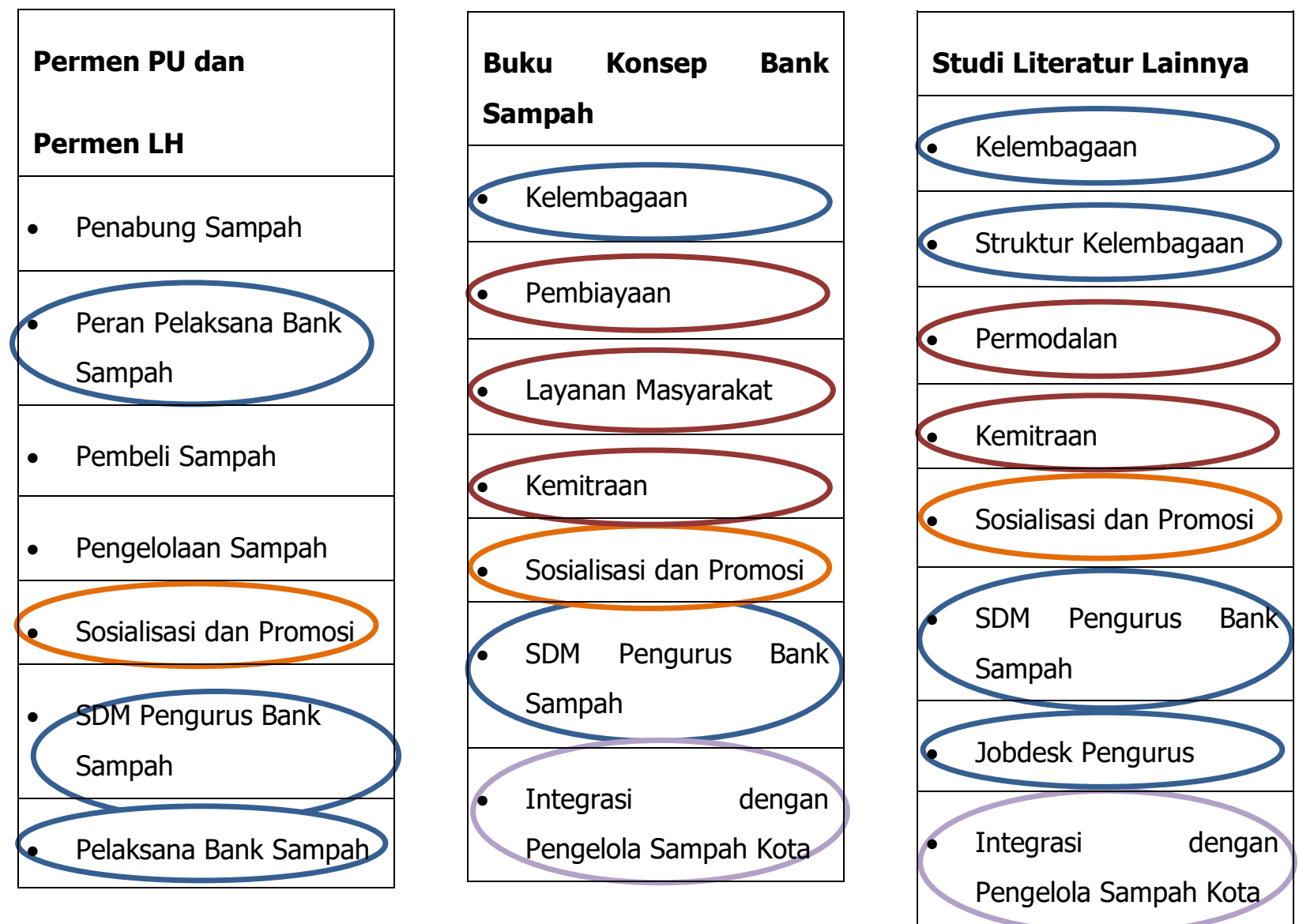

Sumber : Hasil Analisis, 2018

Dapat dilihat pada Tabel 1. bahwa terdapat beberapa kesamaan indikator dari masing-masing sumber acuan, kesamaan tersebut berdasarkan isi pembahasan dari masing-masing poin indikator. Dimana kesamaan pembahasan tersebut ditandai oleh kesamaan warna dari masing-masing kolom, maka kesamaan tersebut dapat dikelompokan menjadi satu indikator.

3. Identifikasi sub-indikator

Identifikasi

sub-indikatordilakukandengancara

yang

samasepertiIdentifikasikomponen, yaitudenganmeninjaudariliteraturutamayaitu IBSR, kemudianhasildaritinjauantersebut di review kembalipadaliteraturpenunjanglainnya

4. Penyusunankriteriapenilaian 
Penyusunankriteriapenilaiandilakukandenganmeninjauliteraturpenunjangkarenapada IBSR belumterdapatkriteriapenilaian.Kriteria penilaian berisikan poin penilaian dengan mempertimbangkan beberapa kondisi yang mungkin terjadi pada subjek penelitian.

5. Pembobotan

Terdapatduametode yang akandigunakanpadapembobotan IBSSK, yaitumetodeAHPdanMetodeEqual Rating.

Metode

akandigunakandalampembobotankomponendanindikatordenganmenggunakankuesion er. Kuesionerberupa perbandingan berpasangan akan diisi oleh empat kategori responden. Empat kategoriresponden tersebutyaituprofesional expert, instansi, akademisi serta pengurus bank sampah.Keempatkategoritersebutdinilaimemilikipengalamanmengenaipersampahankh ususnyadibidang bank sampah. Responden mengisi matriks perbandingan berpasangan dengan angka yang merupakan skala tingkat kepentingan(Suryadi, 2000). Berikut merupakan tabel skala tingkat kepentingan dalam metode AHP :

Tabel 2 Skala Tingkat Kepentingan

\begin{tabular}{|l|l|}
\hline Tingkat Kepentingan & Definisi \\
\hline 1 & Sama penting \\
\hline 3 & Sedikit lebih penting \\
\hline 5 & Jelas lebih penting \\
\hline 7 & Sangat jelas lebih penting \\
\hline 9 & Pasti/mutlak lebih penting \\
\hline $2,4,6,8$ & Jika ragu-ragu antara dua nilai yang berdekatan \\
\hline $1 /(1-9)$ & Kebalikan nilai tingkat kepentingan dari skala $1-9$ \\
\hline
\end{tabular}

Sumber : Saaty, 1986

Proses pengolahan data kuesioner ini dilakukan dengan menggunakan aplikasi Expert Choice II. Proses perhitungan tingkat konsisitensi dari masing-masing responden dilakukan secara otomatis (Dwi, 2014). Setelah itu, untuk responden yang memiliki tingkat konsistensi tinggi, dapat digabungkan dengan menggunakan aplikasi Expert Choice II.Sedangkan, untuk pembobotan Sub-indikator dilakukan dengan cara membagi rata antara nilai maksimum dengan jumlah sub-indikator. Hal ini dikarenakan, jika semua tingkatan indeks menggunakan metode AHP maka akan sulit untuk menjaga tingkat konsistensi hasil pembobotan.

6. Pengolahan data

Setelahpenyusunanindekstelahdilakukan, kemudianakandilakukanpengolahan data berupaagregasidaninterpretasiindeks. Agregasi merupakan penggabungan untuk memperoleh nilai akhir dari suatu indeks (Juwana, 2012).Terdapatduacaradalammelakukanagregasi, yaitumetodearitmatikdanmetodageometri. akandibahascarapemilihannyadarikeduametodetersebut.

Padakajianini, Interpretasi indeks merupakan penyesuaian indeks dengan subjek penelitian, serta menunjukan kesiapan atau nilai dari subjek yang diteliti. Dalam studi ini diperlukan Interpretasi indeks dan akan dibahas cara penentuannya.

\section{HASIL DAN PEMBAHASAN}

\subsection{Identifikasi Komponen}

Identifikasi komponen dilakukan dengan meninjau literatur utama, yaitu IBSR. Kemudian melakukan review kembali dengan literatur penunjang. Berikut merupakan skema dalam melakukan Identifikasi komponen : 


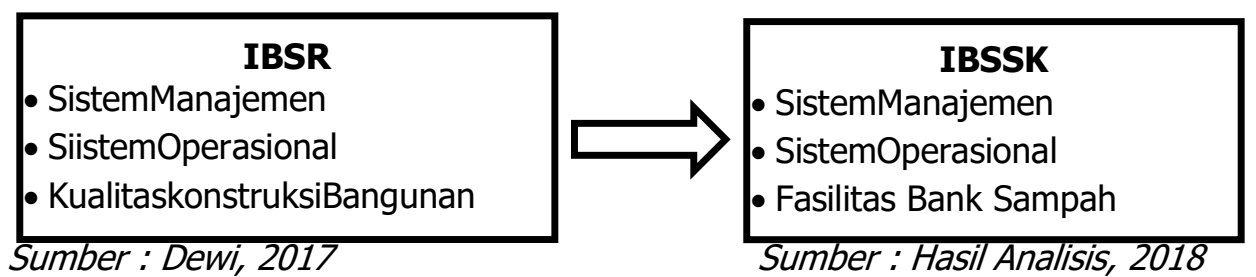

Berikut merupakan pembahasan yang dapat dijadikan komponen dari literatur penunjang :

Tabel 3 Komponen Hasil Desk Study

\begin{tabular}{|l|l|}
\hline Komponen & Sumber \\
\hline Sistem Manajemen & $\begin{array}{l}\text { Permen PU, Permen LH, Buku Konsep } \\
\text { Bank Sampah, Studi Literatur lainnya }\end{array}$ \\
\hline $\begin{array}{l}\text { Sistem Operasional } \\
\text { Fasilitas }\end{array}$ & $\begin{array}{l}\text { Permen PU, Permen LH, Buku Konsep } \\
\text { Bank Sampah, Studi Literatur lainnya }\end{array}$ \\
\hline $\begin{array}{l}\text { Konsep dan Potensi } \\
\text { Sampah }\end{array}$ & Permen PU, Studi Literatur lainnya \\
\hline
\end{tabular}

Sumber : Hasil Analisis, 2018

Komponen yang umumnya terdapat di semua sumber adalah Komponen Sistem Operasional dan Komponen Sistem Manajemen. Maka hal ini mengindikasikan pentingnya komponen tersebut, yang kemudian perlu dijadikan komponen dalam IBSSK dalam studi ini. Sedangkan komponen lain seperti Fasilitas, Konstruksi Bangunan, Kualitas Konstruksi Bangunan serta Sarana dan Prasarana Penunjang akan dibahas dalam Komponen Fasilitas.

\subsection{Identifikasi Indikator}

Identifikasi indikator dilakukan pada masing-masing komponen terpilih pada tahap sebelumnya, yaitu Komponen Sistem Manajemen, Komponen Sistem Operasional serta Komponen Fasilitas Bank Sampah.

\subsubsection{Identifikasi Indikator dalam Komponen Sistem Manajemen}

Dari keempat acuan yang digunakan dalam menentukan indikator, terdapat beberapa indikator yang dapat dikelompokan. Berikut merupakan poin pembahasan yang dibahas dari masing-masing sumber acuan tersebut:

Tabel 4 Indikator dalam Komponen Sistem Manajemen

\begin{tabular}{|l|l|}
\hline \multicolumn{1}{|c|}{ Indikator } & \multicolumn{1}{c|}{ Sumber } \\
\hline Kelembagaan, stuktur kelembagaan, SDM, Jobdesk & $\begin{array}{l}\text { Permen PU, Permen LH, Buku } \\
\text { Konsep Bank Sampah, Studi } \\
\text { Pembiayaan, permodalan, kemitraan }\end{array}$ \\
\hline Sosialisasi dan promosi & \\
\hline Integrasi dengan pengelola sampah kota & \\
\hline \multicolumn{1}{|c|}{ Sumber : Hasil Analisis, 2018 } &
\end{tabular}

Dari Tabel 4diatas maka dapat dilihat, terdapat beberapa indikator yang dapat digabungkan untuk mewakili Komponen Sistem Manajemen, yaitu Indikator Kelembagaan, Indikator Permodalan dan Kemitraan, Indikator Sosialisasi dan Promosi serta Indikator 
Integrasi dengan Pengelola Sampah Kota. Berikut merupakan skema yang menunjukkan perubahan Indikator pada Komponen Sistem Manajemen yang terdapat di IBSR dan IBSSK:

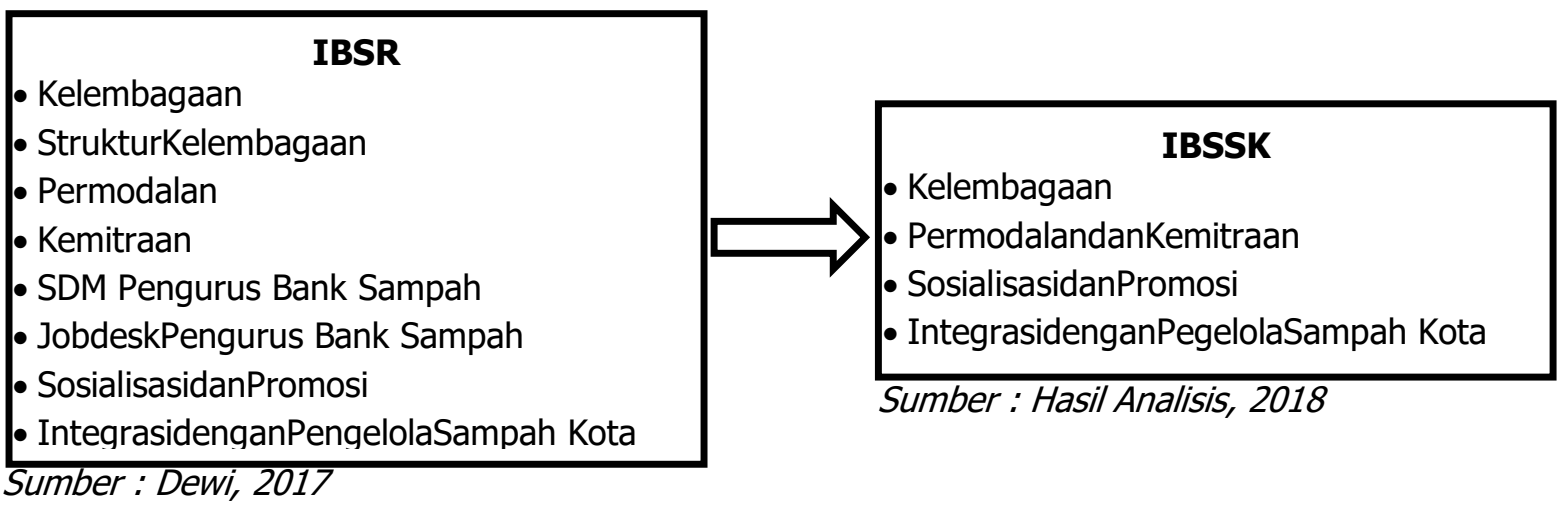

\subsubsection{Identifikasi Indikator dalam Komponen Sistem Operasional}

Dari keempat acuan yang digunakan dalam menentukan indikator, terdapat beberapa indikator yang dapat dikelompokan. Berikut merupakan poin pembahasan yang dibahas dari masing-masing sumber acuan tersebut:

Tabel 5 Indikator dalam Komponen Sistem Operasional

\begin{tabular}{|l|l|}
\hline \multicolumn{1}{|c|}{ Indikator } & \multicolumn{1}{|c|}{ Sumber } \\
\hline $\begin{array}{l}\text { Mekanisme operasional, pelaksana operasional, pengumpulan } \\
\text { dan pengelolaan, jenis sampah, penjemputan sampah, } \\
\text { penetapan harga, waktu operasional }\end{array}$ & $\begin{array}{l}\text { Permen PU, Permen LH, Buku } \\
\text { Konsep Bank Sampah, Studi } \\
\text { Literatur lainnya }\end{array}$ \\
\cline { 1 - 1 } Monitoring, sistem monitoring dan evaluasi & \\
\cline { 1 - 1 } Alat pelindung diri, kesehatan dan keselamatan kerja & \\
\cline { 1 - 1 } Nasabah bank sampah, layanan masyarakat &
\end{tabular}

Sumber : Hasil Analisis, 2018

Terdapat beberapa indikator yang dapat digabungkan untuk mewakili Komponen Sistem Operasional, yaitu Indikator Nasabah, Mekanisme Operasional, Kesehatan dan Keselamatan Kerja, Sistem Monitoring dan Evaluasi serta Sistem Informasi. Berikut merupakan skema yang menunjukkan perubahan Indikator pada Komponen Sistem Operasional yang terdapat di IBSR dan IBSSK:

IBSR
- Nasabah
- JenisSampah yang ditabungkan
- FasilitasOperasional
- PengumpulandanPengelolaanSampah
- PenimbangandanPencatatan
- KesehatandanKeselamatanKerja
- Sistem Monitoring danEvaluasi

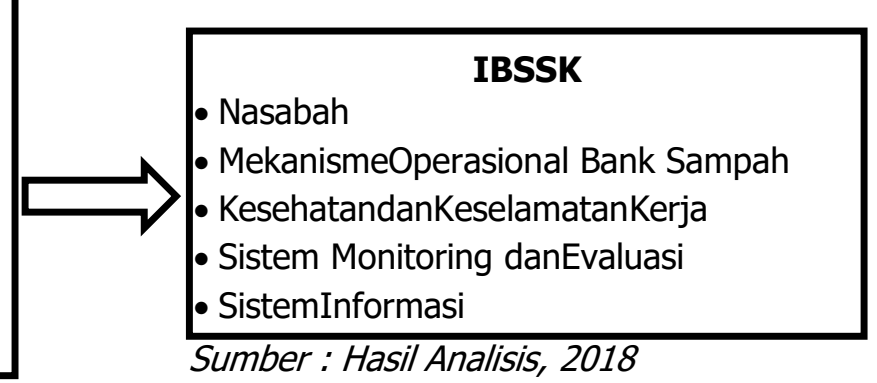

Sumber : Dewi, 2017

\subsubsection{Identifikasi Indikator dalam Komponen Fasilitas Bank Sampah}


Dari keempat acuan yang digunakan dalam menentukan indikator, terdapat beberapa indikator yang dapat dikelompokan. Berikut merupakan poin pembahasan yang dibahas dari masing-masing sumber acuan tersebut:

Tabel 6 Indikator dalam Komponen Fasilitas Bank Sampah

\begin{tabular}{|l|l|}
\hline \multicolumn{1}{|c|}{ Indikator } & \multicolumn{1}{|c|}{ Sumber } \\
\hline Bangunan penunjang, gudang, fasilitas operasional & Permen PU, Permen LH, Buku \\
Konstruksi bangunan, kualitas konstruksi bangunan & $\begin{array}{l}\text { Konsep Bank Sampah, Studi } \\
\text { Literatur lainnya }\end{array}$ \\
\hline Fasilitas 3R, pengolah sampah organik, pengolah sampah anorganik
\end{tabular}

Sumber : Hasil Analisis, 2018

Terdapat beberapa indikator yang dapat digabungkan untuk mewakili Komponen Fasilitas Bank Sampah, yaitu Fasilitas Umum, Fasilitas Bangunan, Fasilitas Operasional dan Fasilitas Penunjang.Berikut merupakan skema yang menunjukkan perubahan Indikator pada Komponen Kualitas Konstruksi Bangunan pada IBSR menjadi Komponen Fasilitas Bank Sampah pada IBSSK:
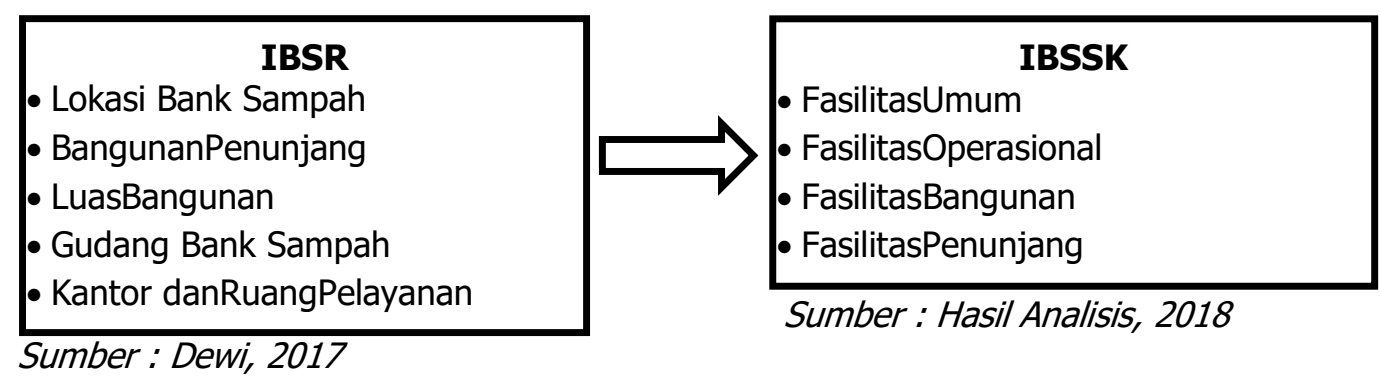

Sumber : Hasil Analisis, 2018

\subsection{Identifikasi Sub Indikator}

Identifikasi sub-indikator dilakukan dengan metode desk study. Penentuan sub-indikator mengacu pada isi pembahasan dari masing-masing indikator yang terseleksi. Jika pembahasan dinilai sama, maka dapat dikelompokan menjadi satu sub-indikator. Indikator Nasabah dibahas dalam semua sumber yang dijadikan acuan pengembangan indikator bank sampah skala kota, hanya saja terdapat beberapa poin yang harus digabungkan dalam menyusun indikator nasabah. Berikut merupakan skema mengenai pembahasan indikator nasabah:

Tabel 7 Indikator Nasabah

\begin{tabular}{|c|c|c|}
\hline Indikator & Sub-Indikator & Sumber \\
\hline \multirow{6}{*}{ Nasabah } & $\begin{array}{l}\text { 1. Jumlah nasabah bertambah } 5-10 \\
\text { perbulan }\end{array}$ & $\begin{array}{l}\text { Permen LH No } 13 \text { Tahun } \\
2012\end{array}$ \\
\hline & 2. Memiliki nasabah individu & \multirow[t]{4}{*}{ 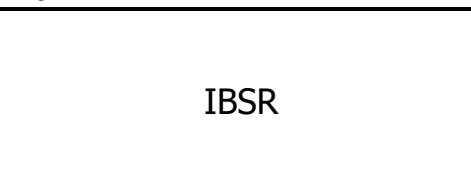 } \\
\hline & 3. Memiliki nasabah kelompok & \\
\hline & 4. Memiliki nasabah isntitusi & \\
\hline & 5. Memiliki nasabah komersil & \\
\hline & 6. Memiliki jumlah nasabah lebih dari 1000 & Studi Literatur lainnya \\
\hline
\end{tabular}

Sumber : Hasil Analisis, 2018

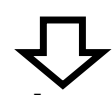

Tabel 8 Indikator Nasabah yang Telah Dikembangkan

\begin{tabular}{|c|l|}
\hline Indikator & Sub Indikator \\
\hline Nasabah & 1. Golongan Nasabah \\
\hline
\end{tabular}




\section{Jumlah Nasabah \\ 3. Penambahan Nasabah}

Sumber : Hasil Analisis, 2018

\subsection{Penyusunan Kriteria Penilaian}

Kriteria penilaian berisikan poin penilaian dengan mempertimbangkan beberapa kondisi yang mungkin terjadi pada subjek penelitian. Maka dalam Penyusunan kriteria penilaian harus memiliki pilihan yang sangat rinci sehingga tidak terdapat kondisi yang tidak tercantum dalam kriteria. Berikut merupakan contoh Penyusunan kriteria penilaian pada SubIndikator SDM:

Tabel 9 Penyusunan Kriteria Penilaian

\begin{tabular}{|l|l|r|}
\hline Sub-Indikator & Kriteria Penilaian & Nilai \\
\hline \multirow{4}{*}{ SDM Bank Sampah } & a. SDM kompeten dan berpengalaman & 100 \\
\cline { 2 - 3 } & b. SDM kompeten tetapi tidak berpengalaman & 50 \\
\cline { 2 - 3 } & c. SDM tidak kompeten tetapi berpengalaman & 50 \\
\cline { 2 - 3 } & d. SDM tidak kompeten dan tidak berpengalaman & 0 \\
\hline
\end{tabular}

Sumber : Hasil Analisis, 2018

Dapat dilihat Tabel 9diatas, pada contoh kriteria penilaian tersebut terdapat dua poin utama yang dijadikan acuan dalam penilaian, yaitu "kompeten" dan "berpengalaman". Kedua poin tersebut berhubungan dengan SDM Bank Sampah, sehingga kedua poin tersebut dijadikan kriteria penilaian pada bank sampah yang dijadikan subjek penelitian. Dimana jika dua poin tersebut terpenuhi maka mendapat nilai 100, sedangkan jika salah satu poin saja yang terpenuhi maka mendapat nilai 50. Tetapi, jika kedua poin tersebut tidak terpenuhi maka tidak mendapat nilai atau 0.

\subsection{Pembobotan Komponen dan Indikator}

Pembobotan komponen dan indikator menggunakan metode AHP, dimana dalam penerapannya metode AHP dilakukan untuk mengetahui rangking dari setiap indikator (Eko, 2014; Putri, 2013). Proses penggunaan Metode AHP ini adalah dengan melakukan penyebaran kuesioner berupa matriks berpasangan pada responden yang dinilai memiliki peran dalam bidang persampahan, yaitu profesional expert, akademisi, instansi serta pengurus bank sampah.

Perhitungan dari hasil kuesioner tersebut menggunakan Expert Choice II, yang nantinya akan diuji tingkat konsistensinya, dan hanya jawaban yang memiliki tingkat konsisten $\leq 0,1$ saja yang nantinya akan digunakan untuk menentukan tingkat kepentingan atau pembobotan pada masing-masing indikator.

\subsubsection{Hasil Pembobotan Komponen}

Pembobotan komponen dilakukan oleh 4 kategori responden. Berikut merupakan diagram yang menunjukan pendapat dari masing-masing responden, serta diagram pembobotan akhir yang digunakan: 


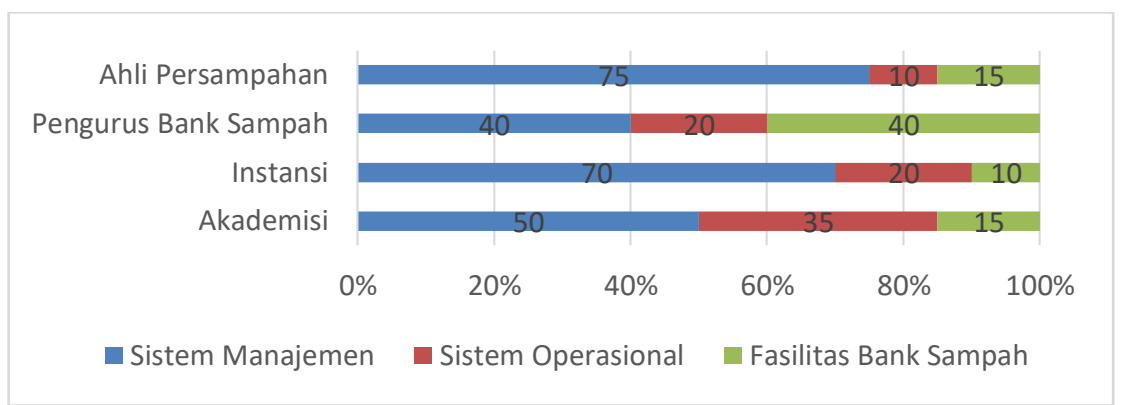

Gambar 1 Diagram Pembobotan Komponen

(Sumber : Hasil analisis, 2018)

Hasil pembobotan komponen dari masing-masing responden akan dianalisis dan hanya responden yang memiliki tingkat konsistensi tinggi yang akan diambil dan digabungkan pendapatnya. Perhitungan konsistensi dilakukan secara otomatis menggunakan aplikasi Expert Choice II. Setelah dilakukan analisis, ternyata pembobotan pada komponen di semua kategori responen memilikitingkat konsistensi yang memenuhi standar $(\leq 0,1)$, sehingga semua pendapatnya dapat digabungkan. Berikut merupakan hasil akhir dari penggabungan pendapat mengenai pembobotan komponen, Komponen Sistem Manajemen (55\%), Sistem Operasional (25\%) dan Fasiltas Bank Sampah (20\%).

\subsubsection{Hasil Pembobotan Indikator}

Perhitungan pembobotan indikator dilakukan dengan cara yang sama seperti pembobotan komponen, hanya saja yang berbeda pada hasil konsistensi antar kategori responden. Berikut merupakan hasil pembobotan menurut masing-masing kategori :

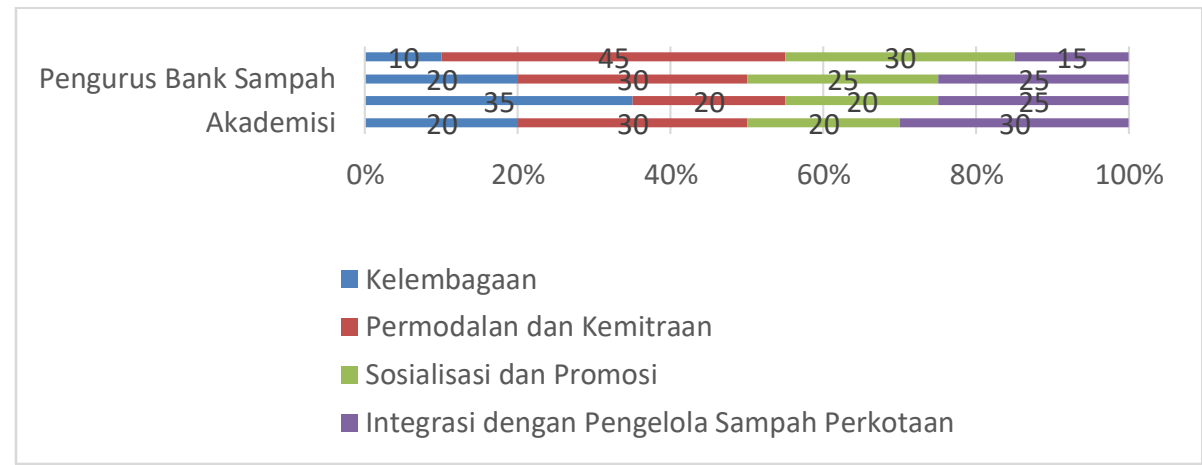

Gambar 2 Diagram Pembobotan SistemManajemen

(Sumber : Hasil analisis, 2018)

Pada Indikator Sistem Manejemen, hanya 3 kategori responden yang konsisten, yaitu instansi, akademisi dan pengurus bank sampah. Dengan bobot akhir yang didapat adalah Indikator Permodalan dan Kemitraan (35\%), Integrasi dengan Pengelola Sampah Kota (30\%), Kelembagaan (20\%) serta Sosialisasi dan Promosi (15\%).

Pembobotan pada Indikator Sistem Operasional hanya menggabungkan pendapat dari dua kategori responden, yaitu akademisi dan pengurus bank sampah. Berikut merupakan hasil pembobotan menurut masing-masing kategori responden : 


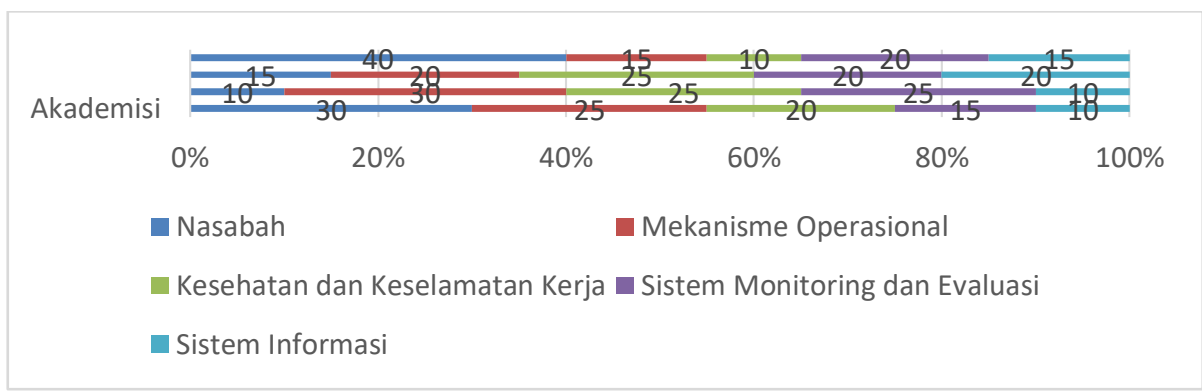

Gambar 3 Diagram Pembobotan SistemOperasional

(Sumber : Hasil analisis, 2018)

Hasil akhir dari pembobotan Indikator Sistem Operasional adalah sebagai berikut, Indikator Kesehatan dan Keselamatan Kerja (25\%), Mekanisme Operasional (20\%), Sistem Monitoring dan Evaluasi (20\%), Nasabah (20\%)serta Sistem Informasi (15\%).Pembobotan pada Indikator Fasilitas Bank Sampah dilakukan penggabungan pendapat dari tiga kategori yaitu akademisi, instansi dan pengurus bank sampah. Berikut merupakan hasil pembobotan menurut masing-masing kategori responden :

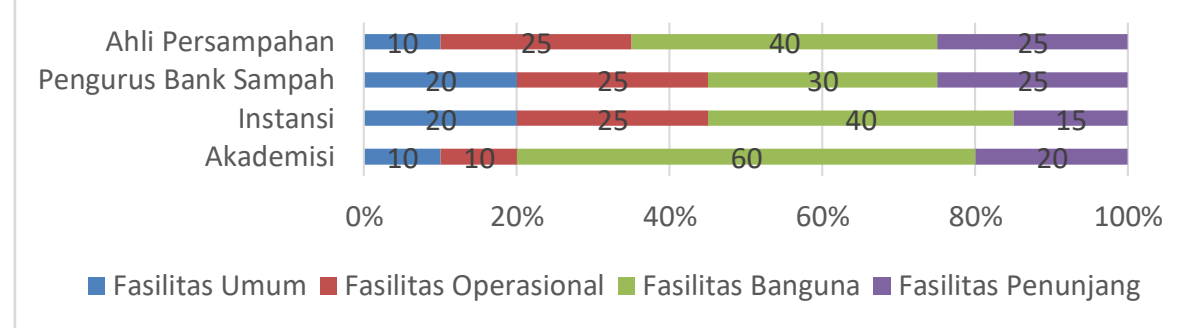

Gambar 4 Diagram Pembobotan Fasilitas Bank Sampah

(Sumber : Hasil analisis, 2018)

Hasil akhir dari pembobotan Indikator Fasilitas Bank Sampah adalah sebagai berikut, Indikator Fasilitas Operasional (45\%), Fasilitas Bangunan (20\%), Fasilitas Penunjang (20\%)serta Fasilitas Umum (15\%).

\subsubsection{Pembobotan Sub Indikator}

Pembobotan pada Sub Indikator dilakukan dengan cara pembagian rata nilai bobot maksimal pada suatu indikator dengan jumlah sub-indikator. Berikut merupakan contoh pembobotan pada Sub Indikator dari Indikator Sistem Monitoring dan Evaluasi :

Tabel 10 Pembobotan Sub-Indikator

\begin{tabular}{|l|l|l|}
\hline Indikator & Sub-Indikator & Bobot \\
\hline \multirow{4}{*}{$\begin{array}{c}\text { Sistem Monitoring } \\
\text { dan Evaluasi }\end{array}$} & 1. Sistem Monitoring & $25 \%$ \\
\cline { 2 - 3 } & 2. Evaluasi & $25 \%$ \\
\cline { 2 - 3 } & 3. Sistem Pengawasan Perbaikan & $25 \%$ \\
\cline { 2 - 3 } & 4. Sistem Penataan & $25 \%$ \\
\hline \multirow{2}{*}{ Sumber : Hasil analisis, 2018} &
\end{tabular}

Pembobotan tersebut didapatkan dengan cara membagi nilai maksimal dari Indikator Sistem Monitoring dan Evaluasi (100\%) dengan jumlah Sub-Indikator yang dimiliki (empat subindikator). Maka didapatkan hasil 25\% untuk masing-masing sub-indikator.

\subsection{Agregasi Indeks}


Agregasi indeks merupakanpenggabungan bobot dari suatu indeks (Nardo,2005). Pada studi ini metode agregasi yang digunakan adalah metode aritmatik. Penggunaan metode aritmatik berdasarkan acuan yang digunakan sebelumnya yaitu studi mengenai indikator bank sampah skala kota, dimana metode untuk melakukan agregasi yang digunakan adalah metode aritmatik. Selain itu, metode aritmatik lebih mudah untuk dipahami dalam pengoperasiannya. Dalam Juwana (2012), digambarkan bahwa metode aritmatik memiliki substitusi yang sempurna sehingga dalam perhitungannya akan menghasilkan nilai rata-rata yang agregat dalam berbagai kasus. Sehingga metode aritmatik tidak dapat terpengaruh jika terdapat nilai bobot yang berbeda saat akan digabungkan. Dari pertimbangan diatas, maka studi ini menggunakan metode aritmatik dalam melakukan agregasi indeks. Contoh agregasi indeks dapat dilihat pada Tabel 11. berikut :

Tabel 11Contoh Agregasi Indeks

\begin{tabular}{|c|c|c|c|c|c|c|c|c|c|}
\hline Komponen & Indikator & $\%$ & $\begin{array}{l}\text { Sub- } \\
\text { Indikator }\end{array}$ & $\%$ & Kriteria & $\%$ & Keterangan & Nilai & $\begin{array}{l}\text { Nilai } \\
\text { Akhir }\end{array}$ \\
\hline \multirow{6}{*}{$\begin{array}{c}\text { Sistem } \\
\text { Manajemen } \\
(40 \%)\end{array}$} & \multirow{6}{*}{$\begin{array}{l}\text { Integrasi } \\
\text { dgn } \\
\text { Pengelola } \\
\text { Sampah } \\
\text { Kota }\end{array}$} & \multirow{6}{*}{20} & \multirow{4}{*}{ 1. Target } & \multirow{3}{*}{50} & $\begin{array}{l}\text { a. memiliki target dan sejalan } \\
\text { dengan target pemerintah }\end{array}$ & 100 & \multirow{3}{*}{$\begin{array}{c}\text { Target } 25 \% \\
\text { pengurangan } \\
\text { dari sumber }\end{array}$} & \multirow{3}{*}{100} & \multirow{3}{*}{50} \\
\hline & & & & & $\begin{array}{l}\text { b. memiliki target tetapi tidak } \\
\text { sejalan dengan target pemerintah }\end{array}$ & 50 & & & \\
\hline & & & & & c. tidak memiliki taget & 0 & & & \\
\hline & & & & & & & & & \\
\hline & & & \multirow{2}{*}{$\begin{array}{l}2 . \\
\text { Kerjasama }\end{array}$} & \multirow[b]{2}{*}{50} & $\begin{array}{l}\text { a. terdapat kerja sama dengan } \\
\text { operator pengelola sampah kota }\end{array}$ & 100 & \multirow[b]{2}{*}{ PD.Kebersihan } & \multirow[b]{2}{*}{100} & \multirow[b]{2}{*}{50} \\
\hline & & & & & $\begin{array}{lll}\text { b. tidak terdapat } & \text { kerjasama } \\
\text { dengan operator } & \text { pengelola } \\
\text { sampah kota } & \\
\end{array}$ & 0 & & & \\
\hline
\end{tabular}

Sumber : Hasil analisis, 2018

Keterangan : $K=$ Komponen, $I=$ Indikator dan SI = Sub-Indikator

Contoh perhitungan Indikator Integrasi dengan Pengelola Sampah Kota sebagai berikut:

Asumsi bahwa pada integrasi dengan pengelola sampah kota memiliki nilai maksimal subindikator 1 dan 2 adalah sama sebesar 20 dengan kriteria penilaian untuk sub indikator 1 dan 2 sebesar $100 \%$, maka perhitungannya adalah :

Nilai Indikator $\quad=\Sigma$ wiSi

$$
=(100 \% \times 20)+(100 \% \times 20)=40
$$

Langkah selanjutnya adalah menghitung nilai komponen. Perhitungan nilai komponen dilakukan dengan cara menjumlahkan semua nilai indikator pada suatu komponen terkait, maka perhitungannya adalah :

Nilai Komponen $\quad=\Sigma$ Nilai Indikator Komponen Sistem Manajemen $=40$

Dari perhitungan nilai indikator dan nilai komponen tersebut, maka dapat diperoleh nilai indeks dengan dilakukan penjumlahan pada nilai komponen dari suatu indeks.

\subsection{Interpretasi Indeks}

Interpretasi indeks menunjukan nilai akhir dari suatu subjek yang dijadikan subjek penelitian. Berikut merupakan contoh interpretasi indeks dari beberapa sumber yang akan dijadikan acuan dalam pembuatan skala interpretasi pada IBSSK:

Tabel 12 Contoh Interpretasi Indeks

\begin{tabular}{|l|c|c|c|c|c|}
\hline \multicolumn{2}{|c|}{ CCME WQI* } & \multicolumn{2}{c|}{ NSF WQI* } & \multicolumn{2}{c|}{ WJWSI** } \\
\hline Nilai & Interpretasi & Nilai & Interpretasi & Nilai & Interpretasi \\
\hline $0-44$ & Buruk & $0-25$ & Sangat Buruk & $0-<25$ & Cukup Buruk \\
\hline $45-64$ & Cukup Buruk & $25-50$ & Buruk & $25-<50$ & Buruk \\
\hline
\end{tabular}




\begin{tabular}{l|l|l|l|c|c|c|}
\hline $65-79$ & Sedang & $50-70$ & Sedang & $50-<75$ & Baik \\
\hline $80-94$ & Baik & $70-90$ & Baik & $75-100$ & Sangat Baik \\
\hline $95-100$ & Sangat Baik & $90-100$ & Sangat Baik & & \\
Sumber : *Sutadian, 2017 \\
**Juwana, 2012 \\
Catatan : CCME WQI \\
NSF WQI Canadian Council of Ministers of the Environment \\
WJWSI : National Sanitation Foundation Index \\
: West Java Water Sustainability Index
\end{tabular}

Skala yang digunakan pada ketiga sumber diatas adalah 1-100. Dimana angka 0 menunjukkan nilai minimum dan angka 100 menunjukkan angka maksimum. Skala tersebut akan digunakan juga pada studi ini, karena menggunakan acuan seperti pada Tabel 12. Dimana sumber yang dijadikan acuan tersebut memiliki pembahasan yang sama dengan studi ini, yaitu mengenai penyusunan indeks. Perbedaan dari masing-masing sumber mengenai interpretasi terletak pada pembagian rentang tiap tingkatan. Berikut merupakan skala interpretasi yang akan digunakan untuk IBSSK :

Tabel 13 Interpretasi Indeks

\begin{tabular}{|c|c|}
\hline Agregasi Indeks & Interpretasi \\
\hline $0-<25$ & Sangat Buruk \\
\hline $25-<40$ & Buruk \\
\hline $40-<60$ & Kurang Baik \\
\hline $60-<80$ & Baik \\
\hline $80-100$ & Baik Sekali \\
\hline
\end{tabular}

Sumber : Hasil analisis, 2018

Tabel 13 menunjukkan bahwa pada studi ini memiliki lima tingkatan interpretasi sama seperti pada sumber yang dijadikan acuan yaitu Canadian Council of Ministers of the Environment dan National Sanitation Foundation Index. Hasil Interpretasi merupakan hasil akhir yang menunjukan nilai keseluruhan dari hasil penilaian yang dilakukan dengan penggabungan nilai komponen, indikator dan sub indikator pada indeks. Penetapan lima tingkatan interpretasi dilakukan untuk memberikan gambaran yang lebih rinci terkait kondisi bank sampah yang dinilai (Saffran dkk., 2001). Selain itu, dengan penetapan lima tingkatan interpretasi maka rentang antar interpretasi tidak terlalu jauh sehingga, akan lebih besar juga peluang untuk mendapatkan hasil interpretasi yang baik.

\section{KESIMPULAN}

Indeks Bank Sampah Skala Kota terdiri dari Komponen, Indikator, Sub Indikator dan Kriteria. Berdasarkan hasil analisismaka terdiri dari 3 Komponen yaitu Komponen Sistem Manajemen (40\%), Sistem Operasional (30\%) dan Fasiltas Bank Sampah (30\%). Dalam komponen tersebut terbagi lagi menjadi indikator. Pada Komponen Sistem Manajemen terdapat 4 Indikator, yaitu Indikator Permodalan dan Kemitraan (35\%), Integrasi dengan Pengelola Sampah Kota (30\%), Kelembagaan (20\%) serta Sosialisasi dan Promosi (15\%). Sedangkan pada Komponen Sistem Operasional terdapat 5 Indikator, yaitu Indikator Kesehatan dan Keselamatan Kerja (25\%), Mekanisme Operasional (20\%), Sistem Monitoring dan Evaluasi (20\%), Nasabah (20\%)serta Sistem Informasi (15\%). Pada Komponen Fasilitas terdapat 4 indikator, yaitu Indikator Fasilitas Operasional (45\%), Fasilitas Bangunan (20\%), Fasilitas Penunjang (20\%) serta Fasilitas Umum (15\%). Metode agregasi yang digunakan adalah metode aritmatik. Terdapat lima tingkatan Interpretasi dengan skala 0-100. 


\section{DAFTAR RUJUKAN}

Darmanto, Eko, dkk. (2014). Penerapan Metode AHP untuk Menentukan Kualitas Gula. Universitas Muria : Kudus.

Dewi, Baiq Mardhiyanti Kusuma. (2017). Perencanaan Pengembangan Bank Sampah Resik

PD Kebersihan Menjadi Bank Sampah Skala Kota. Institut Teknologi Nasional. Bandung.

Juwana, Iwan. (2012). Development of a Water Sustainability Index for West Java, Indonesia. Victoria University.

Juliandoni, A. (2013). Pelaksanaan Bank Sampah Berbasis Mayarakat dalam Sistem Pengelolaan Sampah di Kelurahan Gunung Bahagia Balikpapan. Universitas Mulawarman. Samarinda.

Mentari, Febiana Putri dan Ely Setyo Astuti. (2013). Sistem Informasi Penentuan Lokasi TPA Sampah Menggunakan Metode AHP. Politeknik Negeri. Malang.

Nardo, Saisana, dkk. (2005). Handbook on constructing composite indicators: methodology and user guise. OECD Statistic Working Paper : Ispra, Italy.

Nasibu, Iskandar Z. (2009). Penerapan Metode AHP Dalam Sistem Pendukung Keputusan Penempatan Karyawan Menggunakan Expert Choice.

Padmi, Tri dan Enri Damanhuri. (2010). Diktat Kuliah Pengelolaan Sampah. Departemen Teknik Lingkungan, ITB. Bandung.

Peraturan Menteri Pekerjaan Umum Nomor 3 Tahun 2013 Tentang Penyelenggaraan Prasarana dan Sarana Persamahan Dalam Penanganan Sampah Rumah Tangga dan Sampah Sejenis Sampah Rumah Tangga

Peraturan Menteri Negara Lingkungan Hidup Republik Indonesia Nomor 13 Tahun 2012 Tentang Pedoman Pelaksanaan Reduce, Reuse dan Recycle Melalui Bank Sampah

Retnoningsih, Dwi. (2014). Pemanfataan Aplikasi Expert Choice Sebagai Alat Bantu dalam Pengambilan Keputusan (Studi Kasus: Pemilihan Program Studi di Universitas Sahid Surakarta). Universitas Sahid. Surakarta.

Saaty, T.L. V., (1986). Decision Making for Leaders: The Analytic Hierarchy Process for Decisions in complex world. University of Pittsburgh.

Saffran, K., dkk. (2001). Canadian Water Quality Guidelines For The Protection Of Aquatic Life, Canadian Environmental Quality Guidelines. Canadian Council of

Ministers of the Environment.

Saleh, Siti Ainun. (2013). Buku Konsep Bank Sampah. Internationale Zusammenarbeit (GIZ).

Sutadian, Arief Dhany. (2017). Development of a Cost Effective River Water Quality Index : A Case Study of West Java Province, Indonesia. Victoria University. 